\title{
Pattern- and flash-evoked potentials in the assessment and management of optic nerve gliomas
}

\author{
Z GROSWASSER, A KRISS, AM HALLIDAY, WI McDONALD
}

From the Institute of Neurology, London, UK

SUMMARY Visual evoked potentials were recorded in 25 young patients with optic nerve glioma. In only eight patients could pattern responses be recorded from the affected eyes and these were invariably abnormal. In nine cases with no pattern responses it was still possible to elicit flash responses from the affected eyes. Six patients showed pattern evoked potential changes indicating involvement of fibres from the fellow eye crossing at the chiasm. Serial recording showed a remarkable improvement in the pattern responses of two patients. Flash responses were far less sensitive and less reliable than pattern responses in monitoring patients.

The management of intrinsic tumours of the optic nerve in childhood presents considerable difficulties. Because they are rare, the experience of the individual physician or surgeon is limited. The commonest is optic nerve glioma, but the clinical and radiological features of optic nerve sheath meningioma are very similar. The gliomas are usually of low grade and may follow an indolent course for many years. Some, however, progress rapidly with increasing proptosis and visual loss. The existence of such cases raises the question whether an attempt at radical cure should be made.' A necessary prerequisite for such an attempt is to establish that the tumour is confined to one optic nerve. In trying to do this, we have used the visual evoked potential (VEP) in addition to charting of the visual fields, CT scanning and, in the past, air encephalography. In the present paper, we describe pattern- and flash-VEP findings to determine the value of pattern half-field stimulation and serial recordings in assessing the clinical status of these patients. VEP studies of optic nerve glioma in childhood do not appear to have been published. Kupersmith $e a^{2}{ }^{2}$ described pattern and flash VEP findings in four adults with chiasmal glioma. Although these patients had relatively good acuities (6/12 or better), pattern responses were absent or very severely attenuated, but flash responses were somewhat better preserved.

Address for reprint requests: Dr A Kriss, The National Hospital for Nervous Diseases, Queen Sq, London WC1N 3BG, UK.

Received 11 January 1985. Accepted 26 January 1985.

\section{Methods}

The clinical and evoked potential data was reviewed in 29 patients referred for VEP examination with a clinical diagnosis of optic nerve glioma. Four cases were excluded, two because there was no tumour (radiologically (1) or on surgical exploration (1)) and two because they had different final diagnoses (lymphosarcoma (1) and meningioma (1)). Table 1 shows clinical details of the remaining 25 cases $(21$ females, four males). The presence of tumour in optic nerve and/or chiasm was confirmed by exploration in 13 patients and by CT scan or air encephalography in 12 patients. In the former group, nine were resected, two were biopsied with resection and two were inspected only. The histology of the 11 specimens with an adequate histological examination revealed the characteristic appearance of a low-grade glioma. One patient (case 2) was found to have both a meningioma and a glioma.

Patients were aged between 2 and 29 years (mean 11.3 yrs, SD 6.8) with over half $(14 / 25)$ being 10 years or under at their first VEP recording. Seven patients were tested only once and the remainder were recorded on several occasions, with a mean follow-up interval of 20 months (range 2-52 months). Silver/silver chloride EEG electrodes were attached to the scalp with collodion and were placed on a line $5 \mathrm{~cm}$ and $10 \mathrm{~cm}$ to the left and right of a midline electrode sited $5 \mathrm{~cm}$ above the inion. All occipital electrodes were referred to a midfrontal electrode located $12 \mathrm{~cm}$ above the nasion. In addition, electrodes were also placed at the inion and either $2.5 \mathrm{~cm}$ above and $5 \mathrm{~cm}$ below the inion (referred to midfrontal), or alternatively, in order to monitor the ERG, midway along the lower eyelid and at the outer canthus of each eye. A checkerboard was back-projected onto a screen and viewed by the patient from a distance of one metre; full field $\left(0-16^{\circ} \mathrm{r}\right)$ and half-field $\left(0-16^{\circ} \mathrm{r}\right)$ stimuli were made up of $50^{\prime}$ black and white checks having luminances of 8 and $227 \mathrm{~cd} / \mathrm{m}^{2}$, respectively. Pattern reversal stimulation was effected by a 
Table 1 Clinical details of patients

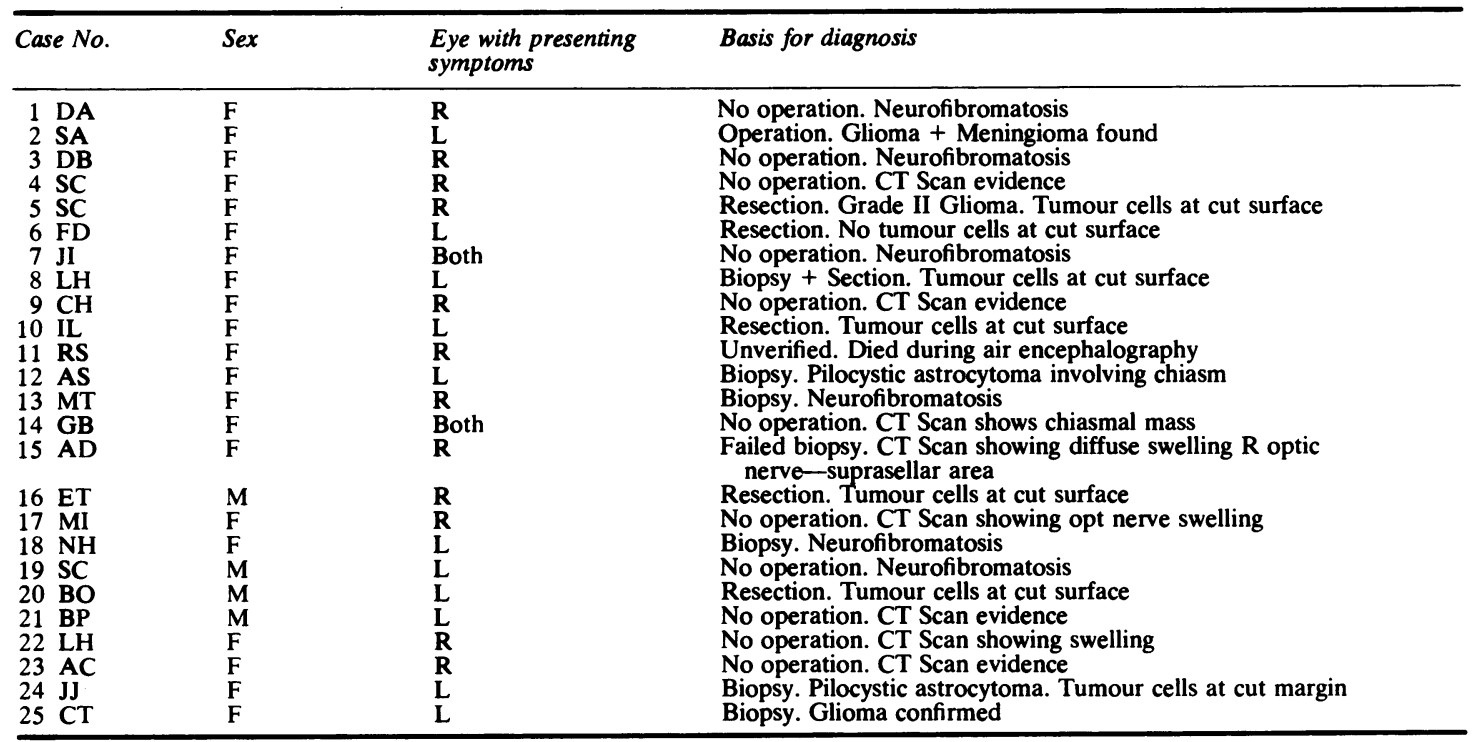

rapid (10 ms duration) lateral displacement of the checkerboard through one square. Most of the patients (16/25, $64 \%$ ) had their VEPs recorded with a flash stimulus which had a peak intensity of $1 \times 10^{6} \mathrm{~cd} / \mathrm{m}^{2}$ and was presented at the rate of once every second.

Eight channels of EEG were analysed over an epoch of 320 ms, using a PDP-12 computer with either 128 or 256 samples at a sampling rate of 400 or $800 \mathrm{~Hz}$, respectively. Two hundred sweeps were averaged for pattern stimulation and 100 for flash stimulation. Recording amplifiers had a bandpass of $0 \cdot 1$ to $2 \mathrm{KHz}(-3 \mathrm{~dB}$ points).

\section{Results}

\section{Findings on the affected eye}

Table 2 gives the visual acuity and VEP data at the time of the first recording for all patients listed in table 1. Latency and amplitude values of the major positive component of pattern and flash responses recorded at the mid-occipital electrode following full field stimulation is given. Measures which are beyond the limits of normal (2.5 SD) appear in italics. The upper limit of normal for latency is $115 \mathrm{~ms}$ and the inter-ocular amplitude difference, $7 \mu \mathrm{V} .^{3}$ "NRD" denotes that stimulation was attempted but no response was detectable, while a cross indicates stimulation was not performed as either the optic nerve had been excised or the patient reported no perception of light from the eye concerned. It is worth noting, however, that two out of five patients, who ostensibly had no perception of light but nonetheless received flash and pattern stimulation, produced clearly recognisable flash responses from the affected eye.

Acuity in the affected eye was $6 / 24$ or less in $80 \%(20 / 25)$ of the patients and $6 / 12$ or better for the fellow eye in $84 \%(21 / 25)$.

Pattern responses could be recorded from the affected eye in only eight of the patients, although all 25 showed responses from the fellow eye. The responses from the affected eye were invariably abnormal, generally consisting of small broad midline positivities of degraded waveform, peaking at 110-140 ms (fig 1). In 13 patients, the pattern response was not detectable, and in four no recording was attempted. The flash response was tested in 16 of the 25 patients and was present in the affected eye in all except three cases. Table 3 summarises the relative incidence of flash and pattern EPs in the same patient. Pattern EPs were elicited following stimulation of the affected eye in only three of the 15 patients who received both pattern and flash stimulation. However, 12 of these patients still had flash EPs. In only three of the 16 patients tested were flash EPs also unobtainable.

Figure 2 shows the pattern (upper traces) and flash (lower traces) EPs of a 14-year-old girl (RS) who had acuity reduced to the perception of hand movement for the affected eye and $6 / 5$ for the fellow eye. The pattern response was abolished from the affected eye, whilst the flash EP is still well preserved and of relatively large amplitude. It shows, however, a clear delay for the major positive peak as compared with that of the response from the fellow 
Pattern- and flash-evoked potentials in the assessment and management of optic nerve gliomas

Table 2 Acuity and VEP data

\begin{tabular}{|c|c|c|c|c|c|c|c|c|c|c|c|c|}
\hline \multirow[t]{3}{*}{ Case } & \multirow{3}{*}{$\begin{array}{l}\text { Age at } \\
1 \text { st VER } \\
\text { recording } \\
\text { (yr) }\end{array}$} & \multirow{3}{*}{\multicolumn{2}{|c|}{$\begin{array}{l}\text { Acuity at 1st VER } \\
\text { Recording } \\
L\end{array}$}} & \multirow{3}{*}{$\begin{array}{l}\text { Eye } \\
\text { showing } \\
\text { signs }\end{array}$} & \multicolumn{4}{|c|}{ Affected eye response to } & \multicolumn{4}{|c|}{ Fellow eye response to } \\
\hline & & & & & \multicolumn{2}{|l|}{ Pattern } & \multicolumn{2}{|l|}{ Flash } & \multicolumn{2}{|l|}{ Pattern } & \multicolumn{2}{|l|}{ Flash } \\
\hline & & & & & Lat $m s$ & $A m p \mu V$ & Lat ms & $A m p \mu V$ & Lat ms & $A m p \mu V$ & Lat ms & $A m p \mu V$ \\
\hline $\begin{array}{ll}1 & \mathrm{DA} \\
2 & \mathrm{SA} \\
3 & \mathrm{DB} \\
4 & \mathrm{SC} \\
5 & \mathrm{SC} \\
6 & \mathrm{FD} \\
7 & \mathrm{JI} \\
8 & \mathrm{LH} \\
9 & \mathrm{CH} \\
10 & \mathrm{IL} \\
11 & \mathrm{RS} \\
12 & \mathrm{AS} \\
13 & \mathrm{MT} \\
14 & \mathrm{~GB} \\
15 & \mathrm{AD} \\
16 & \mathrm{ET} \\
17 & \mathrm{MI} \\
18 & \mathrm{NH} \\
19 & \mathrm{SC} \\
20 & \mathrm{BO} \\
21 & \mathrm{BP} \\
22 & \mathrm{LH} \\
23 & \mathrm{AC} \\
24 & \mathrm{JJ} \\
25 & \mathrm{CT} \\
\text { Mean } \\
\text { SD } \\
\mathrm{N}\end{array}$ & $\begin{array}{c}10 \\
8 \\
5 \\
11 \\
9 \\
5 \\
8 \\
6 \\
14 \\
8 \\
11 \\
5 \\
12 \\
14 \\
24 \\
7 \\
5 \\
13 \\
6 \\
26 \\
2 \\
10 \\
19 \\
29 \\
16 \\
11 \cdot 3 \\
6 \cdot 8 \\
25\end{array}$ & $\begin{array}{l}6 / 4 \\
6 / 24 \\
6 / 6 \\
6 / 5 \\
6 / 9 \\
\mathrm{PL} \\
6 / 60 \\
\mathrm{PL} \\
6 / 4 \\
\mathrm{NPL} \\
6 / 5 \\
\mathrm{NPL} \\
6 / 6 \\
6 / 12 \\
6 / 4 \\
6 / 5 \\
6 / 9 \\
6 / 12 \\
\mathrm{CF} \\
\mathrm{NPL} \\
\times \\
6 / 18 \\
6 / 5 \\
\mathrm{NPL} \\
6 / 36\end{array}$ & $\begin{array}{l}\text { PL } \\
6 / 6 \\
6 / 18 \\
6 / 36 \\
\text { NPL } \\
6 / 6 \\
6 / 60 \\
6 / 4 \\
6 / 24 \\
6 / 4 \\
\text { HM } \\
6 / 6 \\
\text { PL } \\
6 / 12 \\
\text { PL } \\
\text { NPL } \\
6 / 9 \\
6 / 4 \\
6 / 6 \\
6 / 5 \\
\times \\
\text { NPL } \\
\text { NPL } \\
6 / 5 \\
6 / 36\end{array}$ & $\begin{array}{l}\text { R } \\
\text { L } \\
\text { R } \\
\text { R } \\
\text { R } \\
\text { L } \\
\text { Both } \\
\text { L } \\
\text { R } \\
\text { L } \\
\text { R } \\
\text { L } \\
\text { R } \\
\text { Both } \\
\text { R } \\
\text { R } \\
\text { R } \\
\text { L } \\
\text { L } \\
\text { L } \\
\text { L } \\
\text { R } \\
\text { R } \\
\text { L } \\
\text { L }\end{array}$ & $\begin{array}{l}\text { NRD } \\
138 \\
125 \\
\text { NRD } \\
\text { NRD } \\
\text { NRD } \\
140 \\
130 \\
\text { NRD } \\
\times \\
\text { NRD } \\
\text { NRD } \\
\text { NRD } \\
102 \\
\text { NRD } \\
\times \\
144 \\
104 \\
\text { NRD } \\
\text { NRD } \\
\times \\
\text { NRD } \\
\times \\
\text { NRD } \\
130 \\
126 \cdot 6 \\
15 \cdot 8 \\
8\end{array}$ & $\begin{array}{l}\text { NRD } \\
8 \cdot 2 \\
10 \cdot 3 \\
\text { NRD } \\
\text { NRD } \\
\text { NRD } \\
3 \cdot 4 \\
2 \cdot 3 \\
\text { NRD } \\
\times \\
\text { NRD } \\
\text { NRD } \\
\text { NRD } \\
0 \cdot 4 \\
\text { NRD } \\
\times \\
17 \cdot 6 \\
14 \cdot 5 \\
\text { NRD } \\
\text { NRD } \\
\times \\
\text { NRD } \\
\times \\
\text { NRD } \\
8 \cdot 3 \\
8 \cdot 13 \\
6 \cdot 0 \\
8\end{array}$ & $\begin{array}{l}160 \\
119 \\
136 \\
168 \\
\text { NRD } \\
163 \\
142 \\
\times \\
122 \\
\times \\
124 \\
150 \\
120 \\
\times \\
123 \\
\times \\
\times \\
\times \\
\times \\
\text { NRD } \\
170 \\
119 \\
\times \\
\text { NRD } \\
\times \\
139 \cdot 7 \\
19 \cdot 4 \\
13\end{array}$ & $\begin{array}{l}11 \cdot 0 \\
25 \cdot 9 \\
27 \cdot 3 \\
1 \cdot 3 \\
\text { NRD } \\
14 \cdot 1 \\
11 \cdot 3 \\
\times \\
10 \cdot 0 \\
\times \\
5 \cdot 4 \\
17 \cdot 7 \\
18 \cdot 6 \\
\times \\
4 \cdot 0 \\
\times \\
\times \\
\times \\
\times \\
\text { NRD } \\
37 \cdot 0 \\
18 \cdot 6 \\
\times \\
\text { NRD } \\
\times \\
15 \cdot 6 \\
9 \cdot 7 \\
13\end{array}$ & $\begin{array}{c}106 \\
109 \\
103 \\
107 \\
105 \\
117 \\
96 \\
102 \\
102 \\
110 \\
113 \\
109 \\
112 \\
116 \\
100 \\
104 \\
100 \\
101 \\
97 \\
108 \\
113 \\
115 \\
103 \\
105 \\
129 \\
107 \cdot 2 \\
7 \cdot 2 \\
25\end{array}$ & $\begin{array}{r}12 \cdot 2 \\
40 \cdot 0 \\
29 \cdot 0 \\
20 \cdot 3 \\
24 \cdot 2 \\
7 \cdot 1 \\
3 \cdot 0 \\
26 \cdot 6 \\
10 \cdot 4 \\
10 \cdot 5 \\
9 \cdot 4 \\
17 \cdot 6 \\
10 \cdot 3 \\
5 \cdot 4 \\
13 \cdot 8 \\
31 \cdot 3 \\
20 \cdot 8 \\
25 \cdot 5 \\
4 \cdot 3 \\
9 \cdot 6 \\
27 \cdot 4 \\
12 \cdot 9 \\
13 \cdot 7 \\
33 \cdot 3 \\
10 \cdot 7 \\
17 \cdot 2 \\
9 \cdot 9 \\
25\end{array}$ & $\begin{array}{l}101 \\
102 \\
135 \\
158 \\
105 \\
134 \\
142 \\
\times \\
98 \\
\times \\
95 \\
110 \\
105 \\
\times \\
110 \\
\times \\
\times \\
\times \\
\times \\
108 \\
142 \\
103 \\
\times \\
105 \\
\times \\
115 \cdot 8 \\
18 \cdot 8 \\
16\end{array}$ & $\begin{array}{l}11 \cdot 8 \\
29 \cdot 1 \\
37 \cdot 1 \\
11 \cdot 3 \\
29 \cdot 5 \\
30 \cdot 0 \\
10 \cdot 9 \\
\times \\
23 \cdot 6 \\
\times \\
15 \cdot 5 \\
32 \cdot 7 \\
16 \cdot 8 \\
\times \\
4 \cdot 0 \\
\times \\
\times \\
\times \\
\times \\
4 \cdot 0 \\
15 \cdot 4 \\
32 \cdot 5 \\
\times \\
17 \cdot 5 \\
\times \\
20 \cdot 1 \\
10 \cdot 6 \\
16\end{array}$ \\
\hline
\end{tabular}

NRD-No response detectable.

$\times$-Recording not attempted (see text).

Values in italics are $2.5 \mathrm{SD}$ above the mean value for a healthy control group.

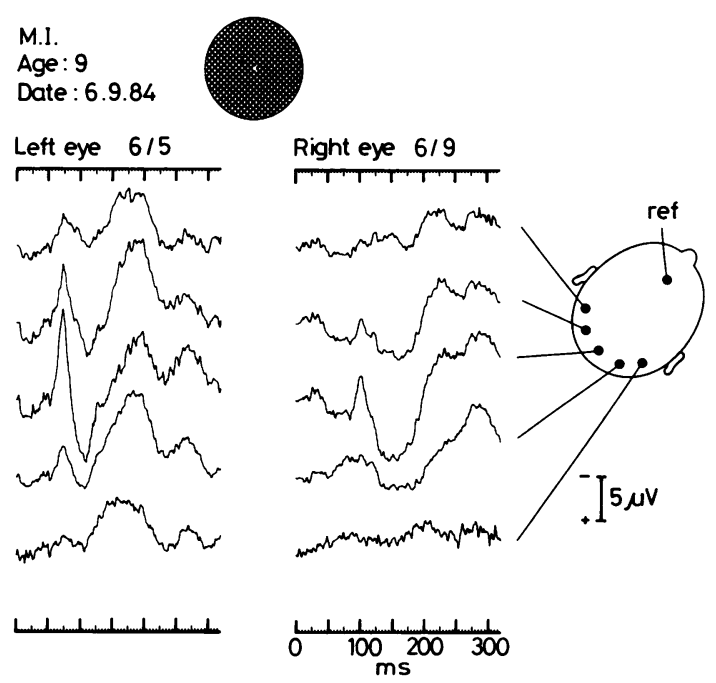

Fig 1 Responses to full-field pattern reversal stimulation in a patient (MI) with right optic nerve glioma and moderately good acuity. The midline main positivity $(P \overline{100})$ from the affected eye is significantly later (by $44 \mathrm{~ms}$ ), smaller and broader compared to that from the fellow eye. eye $(120 \mathrm{~ms}$, as against $103 \mathrm{~ms})$. Another important point of distinction between the pattern and flash response, which will be elaborated on later, is the conspicuous occipital asymmetry in the pattern response from the left (fellow) eye compared to the relatively symmetrical distribution of the corresponding flash response.

Table 4 shows the mean latency and amplitude of the major positive component of pattern and flash responses in those patients in whom they could be recorded. Both pattern and flash responses were significantly delayed for the affected eye $(p \quad 0.05)$ and the delays for the two responses were of a similar magnitude. Although the amplitude of the response from the affected eye was reduced, only the mean inter-ocular amplitude reduction in the pattern response was statistically significant, and this was over twice as large as that for the flash response.

\section{Findings on the fellow eye}

Only a minority of the patients $(5 / 25,20 \%)$ showed evidence of involvement of the fibres from the fellow eye at the initial recording. Figure 3 shows three of the four records of the pattern responses from a patient (SC) who was followed over a period of 6 years. Responses to full field stimulation were sym- 
Table 3 Incidence of pattern and flash responses in the affected and fellow eye

\begin{tabular}{|c|c|c|c|}
\hline & & Affected eye & Fellow eye \\
\hline \multirow[t]{2}{*}{$\begin{array}{l}1 \text { Both pattern and flash tested } \\
\text { Both pattern and flash EPs present } \\
\text { Pattern EP absent, flash EP present } \\
\text { Both pattern and flash EPs absent }\end{array}$} & & $\begin{array}{r}3 \\
9 \\
3 \\
-\end{array}$ & $\begin{array}{r}16 \\
0 \\
0 \\
-\end{array}$ \\
\hline & Subtotal & 15 & 16 \\
\hline \multirow{2}{*}{$\begin{array}{l}2 \text { Pattern only tested } \\
\text { Pattern EP present, flash not tested } \\
\text { Pattern EP absent, flash not tested }\end{array}$} & & $\begin{array}{l}5 \\
1\end{array}$ & $\begin{array}{l}9 \\
0\end{array}$ \\
\hline & Subtotal & 6 & 9 \\
\hline \multirow{2}{*}{$\begin{array}{l}3 \text { Flash only tested } \\
\text { Pattern not tested, flash EP present } \\
4 \text { Neither test performed } \\
\text { Neither pattern nor flash tested }\end{array}$} & & 1 & 0 \\
\hline & Grand total & $\begin{array}{r}3 \\
25\end{array}$ & $\begin{array}{r}0 \\
25\end{array}$ \\
\hline
\end{tabular}

metrically distributed on either side of the midline, and the lateralised P100 component elicited by the left and right half-fields (not shown) was essentially of similar latency and amplitude. No sinister changes were apparent from one recording to the next. The overall reduction in amplitude with time is normal and almost certainly ascribable to maturation.

In contrast to the nearly symmetrical distribution of fellow eye responses in fig 3, the full-field pattern responses in fig 2 show a marked asymmetry. This abnormal distribution is of the type associated with a temporal field defect. The right-sided $P \overline{100}$ component associated with nasal field stimulation is relatively well preserved and recorded over the scalp ipsilateral to the stimulus field while the left-sided $\mathrm{P} \overline{\mathbf{1 0 0}}$ associated with the temporal field is virtually absent. The later positivity seen in the left-sided channels is the contralateral $\mathrm{P} \overline{135}$ component, derived from stimulation of paramacular areas of the nasal field. This abnormal distribution strongly suggests that fibres which cross at the chiasm, subserving vision in the temporal field and derived from the nasal retina of the fellow eye are being affected by the disease.

By the time of the last recording, six patients $(6 / 25,24 \%)$ showed pattern VEP changes indicating involvement of visual pathway fibres of both eyes. In five patients (two with chiasmal glioma), bilateral involvement was apparent at the first recording. In the remaining patient, serial recordings showed progressive changes indicating involvement of fibres from the fellow eye. The clinical and VEP features of these six cases will be described to provide a clearer picture of the type and degree of VEP change which can be observed when the pathway posterior to the optic nerve is affected.

Patient $L H$ was first recorded in October 1978, at the age of 6 yr. In March 1979, her right optic nerve was completely removed. At operation, the appearance and extent of the tumour seemed to indicate that the chiasm had not been infiltrated; however, microscopic examination of the proximal cut end of the nerve subsequent to the operation showed the presence of tumour cells. Since her operation (that is over the last 5 years) the patient has been recorded on eight occasions, at about half-yearly intervals. Acuity of the fellow eye has remained normal and has shown only minor non-progressive fluctuation ranging between $6 / 4$ and $6 / 6-2$.

Figure 4 shows the distribution of responses to full field and half-field stimulation for each recording session and Table 5 summarises the results of all recordings. For full field stimulation, latency and amplitude values for $\mathrm{P} \overline{100}$ recorded from the midoccipital electrode are given. For half-field stimulation, $\mathrm{P} \overline{\mathbf{1 0 0}}$ is normally optimally recorded ipsilateral to the midline and $\mathrm{P} \mathbf{1 0 0}$ measures were taken from responses recorded $5 \mathrm{~cm}$ lateral to the midline on the same side of the scalp as the stimulating half-field.

When the patient was first recorded ( 31 October 1978), the P 100 to full field stimulation of the right (fellow) eye had a normal distribution and latency, as indeed did P100 to independent left and right half-field stimulation. However, two years later, the second recording and the subsequent seven recordings showed a marked increase in the latency of P $\overline{100}$ elicited following temporal field stimulation. Some fluctuation in latency from one recording session to the other was also noted. For the nasal field, $P \overline{100}$ values ranged from $95 \mathrm{~ms}$ to $111 \mathrm{~ms}$ while for the temporal field the variation was greater and extended from $101 \mathrm{~ms}$ to $142 \mathrm{~ms}$. The difference in latency between $\mathrm{P} \overline{\mathbf{1 0 0}}$ s from temporal and nasal half-fields ranged from $1 \mathrm{~ms}$ to $34 \mathrm{~ms}$. The upper limit for temporal/nasal half-field differences in the healthy population is $8 \mathrm{~ms}$. This criterion is derived 
R.S.

Age : 14

Date :17.3.76

Pattern reversal
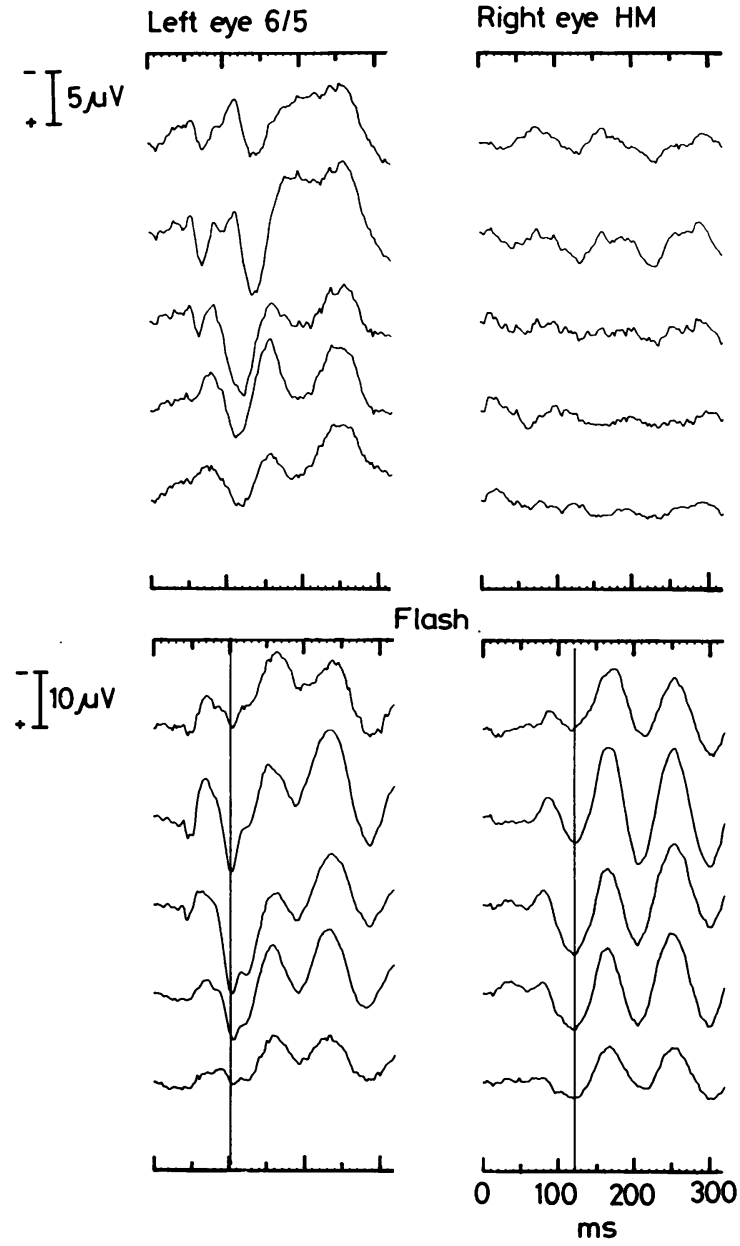

Fig 2 Comparison of responses to full-field pattern reversal stimulation (upper pair of traces) and flash stimulation (lower pair of traces) in a patient $(R S)$ with right optic nerve glioma and very poor acuity. The pattern response from the affected eye is abolished but the flash response is well preserved and clearly delayed compared to the flash response from the fellow eye. Note the asymmetry in the $P \overline{100}$ distribution of the pattern response from the fellow eye suggesting involvement of fibres crossing at the chiasm. No similar asymmetry is apparent for the flash response from the fellow eye.

using data from 84 healthy adult subjects recorded under identical stimulus and recording conditions to the patients (unpublished). Although P100 also fluctuated when comparing recording sessions, the ratio between the amplitude for the temporal and nasal half-field responses never exceeded the range $0 \cdot 5-2 \cdot 0,{ }^{4}$ the criterion for abnormality.

Inter-session fluctuation in the relative emphasis of macular (ipsilateral) and paramacular (contralateral) half-field components was noted. Amplitude and latency variations of $\mathrm{P} \overline{100}$ following full field stimulation could, for the most part, be ascribed to changes in the emphasis of its constituent left and right half-field components, as the full field response closely approximates the algebraic sum of the half field responses.

The last recording from this patient showed a remarkable improvement. The $\mathrm{P} \overline{100}$ component recorded following temporal field stimulation of the right eye was of normal latency, in both absolute and relative terms. Although the latency of the temporal field $\mathrm{P} \overline{\mathbf{1 0 0}}$ was significantly later in recordings previous to the last one, in the penultimate recording there was a qualitative improvement in the waveform of $\overline{\mathbf{P}} \overline{100}$. This consisted mainly of improvement in the peak definition of $\mathrm{P} \overline{100}$ and the succeeding negativity.

Patient AS. This girl first presented for VEP studies at the age of $6 \mathrm{yr}$. She had had a squint and progressive visual loss in the left eye over the previous 4 months. There was no perception of light in the left eye at the time of the last recording and visual acuity was $6 / 6$ from the right eye. At operation on 21 May 1976 a mass was found mainly affecting the left optic nerve, but also involving the chiasm and right optic nerve. Exploration revealed that the left optic tract was also considerably thickened. A biopsy was taken and histological examination indicated a pilocystic astrocytoma corresponding to Grade I of Kernohan's classification. Bilateral shunts were inserted to deal with chronic hydrocephalus. Visual acuity in the right eye remained stable at $6 / 6$ or better for 6 years following biopsy, but at the most recent VEP examination, it was noted to have reduced to $6 / 12-1$.

Table 6 gives the P100 latency and amplitude values from the right eye for five recording sessions. Both full field and half-field results are presented. At the first recording, full field stimulation only was performed. P $\overline{100}$ was present in the midline and left-sided channels while a small negativity at the same latency was seen in right-sided channels. In the next three recordings the responses were degraded compared to those of the first recording. P100 elicited by full field stimulation became progressively smaller (from $17.6 \mu \mathrm{V}$ to $2.5 \mu \mathrm{V}$ ) and later (with latency increasing from $109 \mathrm{~ms}$ to $125 \mathrm{~ms}$ ). Halffield studies showed $P \overline{100}$ to be of longer latency following temporal half-field stimulation as compared to nasal half-field stimulation. 
Table 4 Mean latency and amplitude (with SD in brackets) for the main positivity of the response to full field stimulation from the affected and fellow eyes

\begin{tabular}{|c|c|c|c|c|c|}
\hline & & Affected eye & Fellow eye & Difference & Significance \\
\hline Latency (ms) & $\begin{array}{l}\text { Pattern EP } \\
8 \text { patients } \\
\text { Flash EP } \\
13 \text { patients }\end{array}$ & $\begin{array}{l}126 \cdot 6 \\
(15 \cdot 8) \\
139.7 \\
(20 \cdot 2)\end{array}$ & $\begin{array}{l}107 \cdot 0 \\
(10 \cdot 8) \\
118 \cdot 1 \\
(21 \cdot 0)\end{array}$ & $\begin{array}{l}19 \cdot 6 \\
21 \cdot 6\end{array}$ & $\begin{array}{l}\mathrm{p}<0.05 \\
\mathrm{p}<0.01\end{array}$ \\
\hline Amplitude $(\mu \mathrm{V})$ & $\begin{array}{l}\text { Pattern EP } \\
\text { 8 patients } \\
\text { Flash EP } \\
13 \text { patients }\end{array}$ & $\begin{array}{c}8.13 \\
(+6.0) \\
15.6 \\
(10.2)\end{array}$ & $\begin{array}{c}20.13 \\
(+12.8) \\
20.8 \\
(10.5)\end{array}$ & $\begin{array}{r}12 \cdot 0 \\
5 \cdot 2\end{array}$ & $\begin{array}{l}\mathrm{p}=0.02 \\
\text { NS }\end{array}$ \\
\hline
\end{tabular}

Inter-session fluctuations in responses were also noted in this patient. The full field and nasal halffield responses obtained in the last recording session were better defined and of shorter latency than those of the three previous recording sessions. However, responses from the temporal field were invariably abnormal in all sessions.

Patient $R S$ first presented at the age of $8 \mathrm{yr}$ complaining of headaches and reading difficulties at school. On examination, her right eye was noted to be proptosed and a right optic nerve glioma was diagnosed from radiological studies. At operation, the whole of the chiasm was swollen and infiltrated, demonstrating that the tumour had spread across the other side. This patient was first recorded at the age of 11 years. At this time, only full field stimulation was performed as the half field stimulation technique had not yet been adopted. The record showed a gross asymmetry of the type associated with temporal hemianopia. However, no temporal field defect was noted clinically at this time. Figure 2 shows the responses from the third recording taken at the age of 14 years. The two later records showed evidence of deterioration as responses from the nasal field became "scotomatous" with relative enhancement of the left-sided positive-negativepositive complex derived mainly from stimulation of paramacular areas. The asymmetry of the responses in the first recording suggested spread of the tumour, leading to involvement of fibres crossing from the left eye in the chiasm. The changes in subsequent recordings indicate further spread of the tumour to affect the response from the relatively preserved nasal field with involvement of the noncrossing macular fibres from the left side.

Cases JI and $G B$ both presented with gliomas primarily involving the chiasm. JI has an established diagnosis of Von Recklinhausen's disease. Four years prior to her first VEP recording she had had a course of radiotherapy. CT scan examination a few months before her first VEP showed both optic nerves to be thickened but there was no evidence of hydrocephalus. Her VEPs were recorded in 1976 and 1979. The first recording produced scotomatous waveforms, the response distribution suggesting that they were elicited only from the paramacular areas of the nasal fields of each eye. The recording in 1979 showed evidence of deterioration compared to the 1976 record. Responses could only be elicited following nasal field stimulation of the right eye. Acuities from either eye were $6 / 60$ on each occasion.

The CT scan of patient GB showed enlargement in the area of the chiasm. She had a VEP examination on two occasions (1979 and 1982). At both recording sessions her acuity was $6 / 12$ from each eye. Responses showed no evidence of deterioration from one session to the next. The right eye gave very degraded responses from both temporal and nasal half-fields. Responses from the left eye were better formed and those from the temporal field were significantly later, by $10 \mathrm{~ms}$, compared to nasal field responses.

Case $C T$ was recorded only on one occasion. Only full field stimulation with pattern was tested and the latency of the $\mathrm{P} \overline{100}$ was bilaterally delayed. The asymmetrical distribution of the full field responses suggested an abnormality in the temporal field responses from either eye. The patient had presented with signs indicating a left optic nerve glioma and this was confirmed by biopsy.

\section{Discussion}

The results show the marked changes in visual evoked potentials that occur in the presence of optic nerve glioma. When acuity is moderately impaired, the pattern reversal evoked potential from an affected eye is still present, but usually degraded, smaller and later than that from the fellow eye. When acuity is severely impaired then the pattern response is usually not recordable. These changes are similar to those reported in other conditions causing compression of the anterior visual pathways. ${ }^{5}$ In contrast to this, the flash response can almost always be evoked, even when acuity is grossly reduced, but the only reliable indication of abnormality it can give is an increase in latency. 


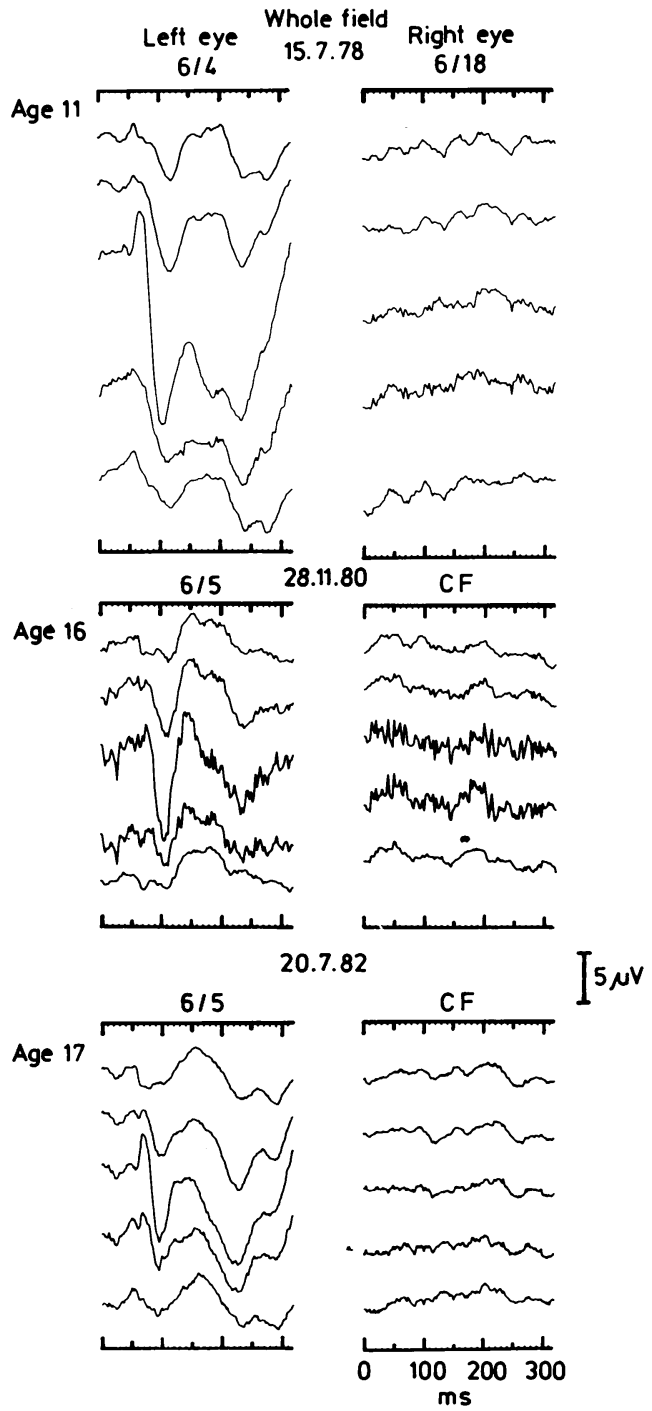

Fig 3 Full-field pattern reversal responses recorded over a period of 6 years from a patient $(S C)$ with a right optic nerve glioma. In each recording, responses from the fellow eye are symmetrically distributed. The overall reduction in amplitude is associated with maturation.

Kupersmith et $a^{2}$ also found the flash response to be better preserved than the pattern response in adult patients with chiasmal glioma.

The present study demonstrated that, unlike the pattern response, the flash response usually tends to have an even, widespread, distribution across the occipital scalp and, because of this, it has little or no clinical value in demonstrating and distinguishing chiasmal or retro-chiasmal involvement. The pattern response, on the other hand, shows excellent sensitivity to such involvement, which is associated with an asymmetrical distribution of the responses to full field stimulation. Half-field stimulation usually demonstrates degraded, abnormal responses from the temporal field of the fellow eye and, in some cases, nasal field responses are also abnormal, though usually to a lesser extent than their counterpart temporal field response. In only a minority of patients in the present study $(24 \%)$ was there evidence of involvement of fibres from both eyes.

Changes in pattern responses associated with visual field defects can best be appreciated with multichannel recording and wide field stimulation (a circular stimulus field greater than $10^{\circ}$ radius). We disagree with Camacho et al, ${ }^{6}$ who claim that a single midline channel will provide adequate information in clinical conditions producing hemifield defects. A montage including laterally placed occipital electrodes, at least $4-5 \mathrm{~cm}$ out from the midline, and separate recordings of responses to left and right half-field stimulation, including an appreciation of the distribution and interaction of macular and paramacular-derived responses, are needed to identify accurately response components (see Blumhardt et al $;^{7}$ Halliday et $\left.a^{8}\right)$.

A remarkable observation in the present study was the improvement encountered in the serial recording of pattern reversal responses of patients $\mathrm{LH}$ and $\mathrm{AS}$. The first record of $\mathrm{LH}$ gave no indication of involvement of fibres from the fellow eye but the second recording two years later, and the next seven recordings taken over the following 3 years, clearly produced degraded, abnormal responses from the temporal field of the fellow eye which were 8-34 ms later than their nasal field counterparts. Although some improvement in waveform was apparent in the later recordings, the difference in latency for the main positive components from the nasal and temporal field was more than $8 \mathrm{~ms}$, thus exceeding the upper limits of normal. However, in the last recording (as in the first), the latency difference for the heteronymous half-fields was $1 \mathrm{~ms}$, well within normal limits; the amplitude and distribution of the temporal field response of the fellow eye were also within the normal range.

These VEP findings clearly suggest a waning of the disease process which, in this case, was not apparent on clinical or radiological testing. The improvement in pattern responses provides support for other clinical and neuropathological evidence ${ }^{10}$ that optic gliomas are capable of spontaneously regressing. Optic gliomas are not unique in this respect as another neuro-ectodermal neoplasm of childhood, peripheral neuroblastoma, also has a 
L.H.

31.10 .78

Age 6

VAR $6 / 4$

25.8.81

Age 9

VAR 614

19.4 .83

Age 11

VAR $6 / 4$

1.5.84

Age 12 VAR $6 / 6$
Whole field
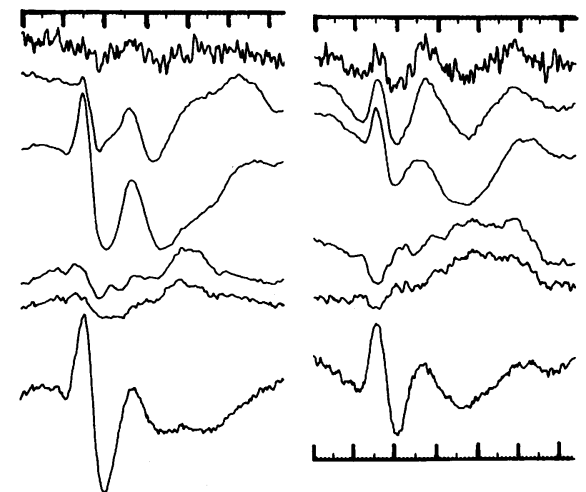

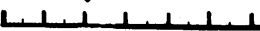
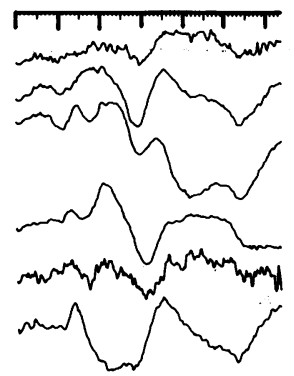

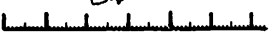
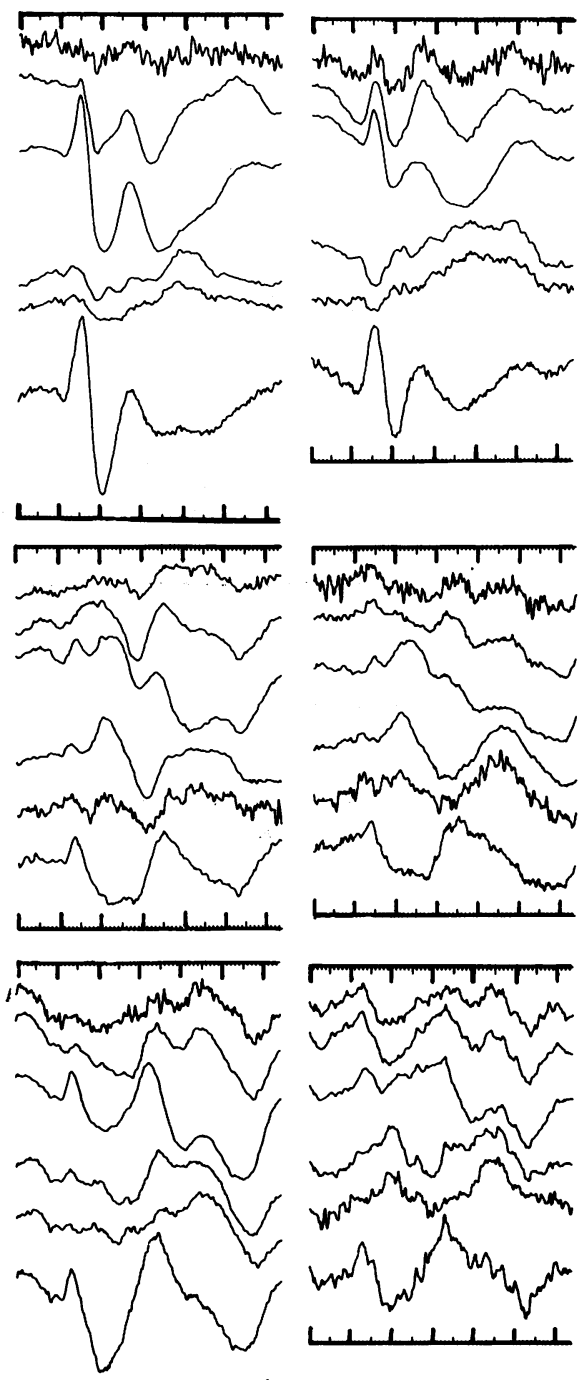

t.
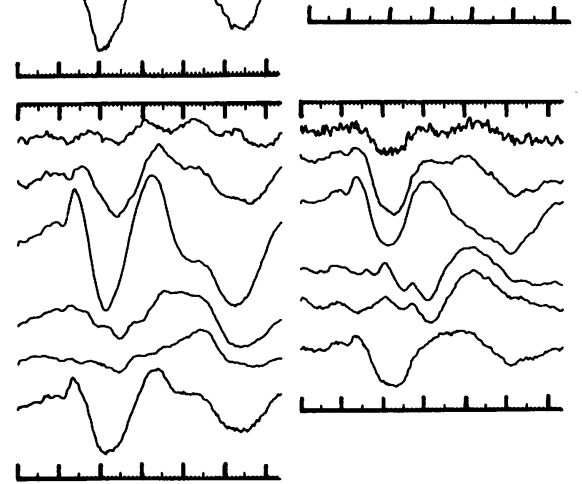

Right half-field

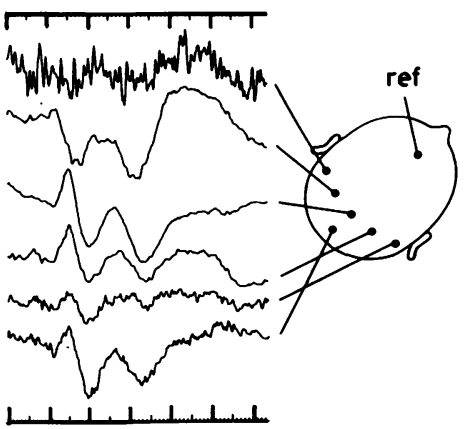

Fig 4 Right (fellow) eye responses to full field (left column) left half field (middle column) and right half field (right column) stimulation for four of the nine recordings performed on patient $L H$. Responses at the first recording (31 Oct 78) are normal with a well-formed major positivity $(P \overline{100})$ in the occipital midline $\overrightarrow{-}$ following full field stimulation, ahd for half field stimulation, a cleafy, lateralised distribution of $P 100^{\circ}$ over the same side of scalp as the stimulated half field. In the nex? two recordings (25 Aug 81 and 18 Apr 83) P $\overline{100}$ is degraded and $\bigcirc$ significantly later following temporal field stimulation.

However, in the last recording May 84) P $\overline{100}$ shows a marked $\overrightarrow{0}$ improvement and is within normats limits. In this patient, a particularly prominent response can be pickedo up at the inion for all recordings.
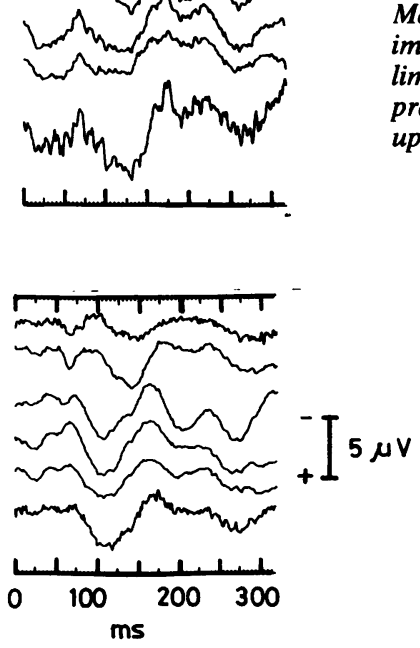
Table 5 Patient $L H$. Full field, left and right half-field values for $P \overline{100}$ from the right (fellow) eye for nine recording sessions

\begin{tabular}{|c|c|c|c|c|c|c|c|c|c|c|}
\hline & \multirow[t]{2}{*}{ Date } & \multirow[t]{2}{*}{ Acuity } & \multicolumn{2}{|c|}{ Full field } & \multicolumn{2}{|c|}{ Left half-field } & \multicolumn{2}{|c|}{ Right half-field } & \multirow{2}{*}{$\begin{array}{l}\text { Half-field } \\
\text { latency } \\
\text { difference } \\
\text { RHF-LHF ms }\end{array}$} & \multirow{2}{*}{$\begin{array}{l}\text { Amplitude ratio } \\
R H F / L H F\end{array}$} \\
\hline & & & $L(m s)$ & $A(\mu V)$ & $L(m s)$ & $A(\mu V)$ & $L(m s)$ & $A(\mu V)$ & & \\
\hline $\begin{array}{l}1 \\
2 \\
3 \\
4 \\
5 \\
6 \\
7 \\
8 \\
9\end{array}$ & $\begin{array}{l}31 \text { Oct } 78 \\
9 \text { Sept } 80 \\
17 \text { March } 81 \\
25 \text { Aug } 81 \\
9 \text { Feb } 82 \\
7 \text { Sept } 82 \\
19 \text { Apr } 83 \\
15 \text { Nov } 83 \\
1 \text { May } 84\end{array}$ & $\begin{array}{l}6 / 4 \\
6 / 6-2 \\
6 / 5-3 \\
6 / 4-1 \\
6 / 4-1 \\
6 / 4-2 \\
6 / 4 \\
6 / 4-3 \\
6 / 6+2\end{array}$ & $\begin{array}{r}102 \\
98 \\
114 \\
90 \\
122 \\
113 \\
108 \\
107 \\
108\end{array}$ & $\begin{array}{r}26 \cdot 6 \\
3 \cdot 6 \\
14 \cdot 2 \\
5 \cdot 2 \\
9 \cdot 8 \\
8 \cdot 2 \\
12 \cdot 3 \\
18 \cdot 6 \\
22 \cdot 4\end{array}$ & $\begin{array}{r}100 \\
108 \\
108 \\
97 \\
105 \\
95 \\
100 \\
106 \\
111\end{array}$ & $\begin{array}{r}12 \cdot 6 \\
3 \cdot 0 \\
9 \cdot 4 \\
5 \cdot 8 \\
7 \cdot 1 \\
4 \cdot 6 \\
7 \cdot 6 \\
9 \cdot 8 \\
11 \cdot 0\end{array}$ & $\begin{array}{l}101 \\
142 \\
121 \\
127 \\
120 \\
122 \\
113 \\
114 \\
112\end{array}$ & $\begin{array}{r}11 \cdot 0 \\
4 \cdot 8 \\
5 \cdot 6 \\
8 \cdot 4 \\
5 \cdot 7 \\
6 \cdot 0 \\
9 \cdot 1 \\
8 \cdot 8 \\
9 \cdot 0\end{array}$ & $\begin{array}{r}1 \\
34 \\
13 \\
30 \\
15 \\
27 \\
13 \\
8 \\
1\end{array}$ & $\begin{array}{l}0 \cdot 88 \\
1 \cdot 6 \\
0 \cdot 6 \\
1 \cdot 4 \\
0 \cdot 8 \\
1 \cdot 3 \\
1 \cdot 2 \\
0 \cdot 9 \\
0 \cdot 8\end{array}$ \\
\hline
\end{tabular}

$\mathbf{L}=$ latency. $\mathbf{A}=$ amplitude.

Table 6 Patient AS. Full field, left and right half-field values for $P \overline{100}$ from the right (fellow) eye for five recording sessions

\begin{tabular}{llllll}
\hline & Date & Acuity & P100 full field & Left half-field & Right half-field \\
\hline 1 & 29 Apr 74 & $6 / 6 \mathrm{pt}$ & $109 \mathrm{~ms}, 17.6 \mu \mathrm{V}$ & Not done & Not done \\
2 & 4 May 76 & $6 / 5$ & $116 \mathrm{~ms}, 8 \cdot 3 \mu \mathrm{V}$ & $116 \mathrm{~ms}, 7 \cdot 5 \mu \mathrm{V}$ & Doubtful response \\
3 & 13 June 80 & $6 / 5$ & $117 \mathrm{~ms}, 4 \cdot 4 \mu \mathrm{V}$ & $116 \mathrm{~ms}, 3 \cdot 0 \mathrm{~V}$ & $147 \mathrm{~ms}, 4 \cdot 5 \mu \mathrm{V}$ \\
4 & 30 Apr 82 & $6 / 5$ & $125 \mathrm{~ms}, 2 \cdot 5 \mu \mathrm{V}$ & $114 \mathrm{~ms}, 4 \cdot 2 \mu \mathrm{V}$ & $136 \mathrm{~ms}, 3 \cdot 3 \mu \mathrm{V}$ \\
5 & 23 June 83 & $6 / 12-1$ & $101 \mathrm{~ms}, 4.0 \mu \mathrm{V}$ & $108 \mathrm{~ms}, 4 \cdot 8 \mu \mathrm{V}$ & $-\mathrm{ve}(115 \mathrm{~ms},-3 \cdot 5 \mu \mathrm{V})$ \\
\hline
\end{tabular}

tendency to regress. A further related point is the infrequency of clinical deterioration following removal of a tumour mass despite evidence of tumour cells in tissue left in the patient. Borit and Richardson ${ }^{10}$ report that histological studies following operation for optic nerve glioma, and postmortem examinations, frequently reveal gliomatous involvement of other parts of the anterior visual pathway. Most of the operated patients in their study showed no further spread following surgery. In the present study, six patients were found to have tumour cells at the posterior margin of the excised portion of the optic nerve. One of these patients was LH; none of the others has to date shown any clinical or VEP evidence of spread of the disease process.

When the present investigation began, our policy in the management of optic nerve glioma was radical; if there was no evidence of involvement of the chiasm or of the fellow optic nerve, the affected nerve was sectioned at the junction with the chiasm. In two cases, a conservative approach was adopted because of visual evoked potential evidence of involvement of the crossing fibres from the opposite side. However, because of the significant proportion of the patients with histological evidence of tumour at the cut end, who do not show evidence of chiasmal involvement, we have abandoned our radical strategy and now reserve surgery for those cases in which there is obvious progression producing complications such as disfiguring proptosis. We recognise however that others prefer a more aggressive approach. It is nevertheless important to avoid surgery which carries the risk of disabling visual impairment when a cure cannot be reasonably expected. Such is the case when the chiasm is involved. The observations in the present paper show that the pattern visual evoked potential is a very sensitive means of detecting such involvement, and the changes in the responses of patient $\mathrm{LH}$ show that even when such involvement is obviously apparent, improvement can occur spontaneously.

Visual evoked potential data can be useful too in conservative management of the patient. Parents of children with optic nerve glioma are not unnaturally anxious about the question of progression. VEP testing is simple and without risk. Stability of serial VEPs provides reassuring confirmation of lack of tumour extension. In such circumstances it is possible to reduce the exposure to the significant amounts of radiation which inevitably accompany serial CT scanning.

We thank Mrs E Halliday for preparing the illustrations and Jack Pitman for technical support.

\section{References}

' Wright JE, McDonald WI, Call NB. Management of optic nerve gliomas. Br J Opthalmol 1980;64:545-52.

${ }^{2}$ Kupersmith MJ, Siegel IM, Carr RE, Ransohoff J, Flamm E, Shakin E. Visual evoked potentials in chiasmal gliomas in four adults. Arch Neurol 1981;38:362-6. 
${ }^{3}$ Halliday AM. Evoked Potentials in Clinical Testing. Edinburgh: Churchill Livingstone, 1982.

${ }^{4}$ Blumhardt LD, Halliday AM. Cortical abnormalities and the visual evoked response. In: Spekreijse $H$, Apkarian P, eds. Visual Pathways: Electrophysiology and Pathology. Documenta Ophathalmologica Proc Ser 1981;27:347-65. The Hague: Junk.

s Halliday AM, Halliday, Elise, Kriss A, McDonald WI, Mushin Joan. The pattern-evoked potential in compression of the anterior visual pathways. Brain 1976;99:357-74.

- Camacho LM, Wenzel W, Aschoff JC. The patternreversal visual evoked potential in the clinical study of lesions of the optic chiasm and visual pathway. In: Carjoun J, Mauguiére F, Revol M, eds. Clinical Applications of Evoked Potentials in Neurology. New York:
Raven Press, 1982:49-59.

${ }^{7}$ Blumhardt LD, Barrett G, Halliday AM, Kriss A. The effect of experimental "scotomata" on the ipsilateral and contralateral responses to pattern reversal in one half-field. Electroencephalogr Clin Neurophysiol 1978;45:376-92.

${ }^{8}$ Halliday AM, Barrett G, Blumhardt LD, Kriss A. The macular and paramacular subcomponents of the pattern evoked response. In: Lehmann D, Callaway E, eds. Human Evoked Potentials. Applications and Problems. New York: Plenum Press, 1979:135-51.

${ }^{9}$ Hoyt WF, Baghdassarian SA. Optic glioma of childhood. Br J Ophthalmol 1969;53:793-8.

${ }^{10}$ Borit A, Richardson EP. The biological and clinical behaviour of pilocystic astrocytomas of the optic pathways. Brain 1983;105: 161-87. 